\title{
A case of INR elevation with remdesivir and warfarin in a hospitalized patient with COVID-19
}

\author{
Liyan Yao*1,2, William Byas ${ }^{1,2}$, Matthew $\mathrm{Li}^{1}$, Merjona Saliaj ${ }^{1}$ \\ ${ }^{1}$ Internal Medicine, Icahn School of Medicine at Mount Sinai, Jamaica, United States \\ ${ }^{2}$ School of Medicine, St. George's University, True Blue, Grenada
}

Received: April 5, 2021

DOI: $10.5430 /$ crim.v8n1p9
Accepted: April 28, 2021

Online Published: May 11, 2021

\begin{abstract}
Treatments for COVID-19 infection have varied widely within the past year. Remdesivir is the only direct-acting antiviral approved by the Food and Drug Administration with demonstrated efficacy in the management of patients with COVID-19. ${ }^{[1]}$ Commonly reported adverse effects include hepatotoxicity and gastrointestinal symptoms such as nausea and diarrhea. Less common adverse effects include respiratory toxicity, cardiovascular toxicity and nephrotoxicity. ${ }^{[2]}$ We report a case of international normalized ratio (INR) prolongation in a COVID-19 patient receiving concomitant warfarin and remdesivir therapy.
\end{abstract}

Key Words: Remdesivir, Warfarin, SARS-CoV-2, COVID-19, Hematology

\section{INTRODUCTION}

Remdesivir (Veklury) is a broad-spectrum antiviral nucleotide prodrug with potent in vitro activity against a range of RNA viruses including SARS-CoV-2. ${ }^{1]}$ Remdesivir is currently the only direct-acting antiviral approved by the Food and Drug Administration (FDA) for the treatment of Coronavirus Disease 2019 (COVID-19). ${ }^{[2]}$ In a randomized placebo-controlled trial of hospitalized patients with COVID-19, remdesivir in conjunction with standard of care demonstrated a shorter median time to recovery of 10 days compared to 15 days in the placebo group. ${ }^{[3]}$ However, results of a multinational open-label randomized trial did not demonstrate any reduction in rates of in-hospital mortality or requirement for mechanical ventilation. ${ }^{[4]}$

Numerous adverse effects of remdesivir have been identified. Commonly reported adverse effects include hepatic enzyme elevations, gastrointestinal symptoms, respiratory failure or acute respiratory distress syndrome, hypotension, atrial fibril- lation, and acute kidney injury. ${ }^{[5,6]}$ The impact of remdesivir use on the coagulation profile is not well described. As of February 2021, there is only one case reporting elevation of the international normalized ratio (INR) after remdesivir initiation with concomitant warfarin therapy. ${ }^{[7]}$ We present a case of remdesivir-induced INR elevation with concomitant warfarin therapy in a hospitalized patient with COVID-19 pneumonia.

\section{CASE PRESEntation}

A 68-year-old African American male with a past medical history of atrial-fibrillation on warfarin, asthma, mitral valve replacement, hypertension, hypothyroidism, hyperlipidemia, cholecystitis, chronic kidney disease stage 3 , presented to the emergency department with complaints of left upper quadrant pain for three days since initial onset. The patient describes the onset of pain as sudden, intermittent, cramping in quality, non-radiating, and exacerbated with movement.

*Correspondence: Liyan Yao; Email: lyao@sgu.edu; Address: 82-68 164th St, Jamaica, NY 11432, USA. 
He had a confirmed COVID-19 infection diagnosis six days prior to presentation. The patient is a former smoker and resides in an apartment with a roommate who was also diagnosed with COVID-19 at the same time he was. He admits to mild shortness of breath upon exertion and a productive cough with blood specked, white phlegm. He denies chest pain, nausea, vomiting, diarrhea, palpitations, anosmia or ageusia. His home medications include warfarin $4 \mathrm{mg}$ at bedtime Monday and Thursday and $10 \mathrm{mg}$ at bedtime the remaining days, albuterol $90 \mathrm{mcg} / \mathrm{act} 2$ puffs inhaled every six hours as needed, budesonide-formoterol 80-4.5 mcg/act 2 puffs two times a day, diltiazem $360 \mathrm{mg}$ daily, hydrochlorothiazide $25 \mathrm{mg}$ daily, levothyroxine $150 \mathrm{mcg}$ daily, lisinopril $40 \mathrm{mg}$ daily, metoprolol $25 \mathrm{mg}$ daily, and rosuvastatin $20 \mathrm{mg}$ daily. Twelve days prior to admission, the patient's INR at our institution's Coumadin Clinic was reported at 2.6.

On initial evaluation, the patient was alert and oriented to person, place, and time. The patient's cardiovascular exam yielded normal rate, irregular rhythm, with S1 and S2 appreciated without any murmurs, rubs, or gallops. Pulmonary exam yielded benign findings with good bilateral air entry and movement with no wheezing or rales appreciated. Chest radiography was obtained which showed reticular markings consistent with atelectasis or edema. Computed tomography (CT) of the abdomen/pelvis without contrast was also obtained and showed the impression of minimal patchy ground-glass opacities in the left lower lobe. Repeat polymerase chain reaction test on presentation was positive for COVID-19 infection. The patient was subsequently admitted for confirmed COVID-19 pneumonia and was initiated on azithromycin $500 \mathrm{mg}$ daily, ceftriaxone 1,000 mg daily, dexamethasone $6 \mathrm{mg}$ daily, vitamin C $1,000 \mathrm{mg}$, zinc sulfate 220 $\mathrm{mg}$, and remdesivir $200 \mathrm{mg}$ once followed by $100 \mathrm{mg}$ daily. The patient's home warfarin therapy for atrial fibrillation was resumed in the evening.

The patient's baseline INR upon hospital admission was 2.3. Based on the day of the week, the patient received $10 \mathrm{mg}$ of warfarin in the evening of admission day 1 . The subsequent INR values throughout the hospital course were significantly elevated: day 2-4.1, day 3-4.6 and day 3 repeat -4.9 as shown in Table 1. The patient's hepatic function panel and platelet count were within normal limits throughout the entire hospital course. The patient was hemodynamically stable on hospital day 3 and was discharged with outpatient follow-up with the Coumadin Clinic for INR monitoring. On day 3 of outpatient follow up, the patient's INR was still found to be elevated at 3.6. A therapeutic INR was achieved on day eight of outpatient follow up as shown in Table 2. The patient's inpatient and outpatient INR trends alongside when remdesivir was started and discontinued can be seen in Figure 1.

Table 1. Patient's anticoagulation profile during in-patient hospital course

\begin{tabular}{|c|c|c|c|c|c|}
\hline Inpatient Day & PT & INR & $\begin{array}{l}\text { Warfarin } \\
\text { Dose }\end{array}$ & Remdesivir & Concomitant Therapy \\
\hline $\begin{array}{l}\text { Day } 1 \\
\text { (Admission) }\end{array}$ & 26.4 & 2.3 & $10 \mathrm{mg}$ & $\begin{array}{l}200 \quad \mathrm{mg} \quad \mathrm{IV} \\
\text { loading dose }\end{array}$ & $\begin{array}{l}\text { Azithromycin }(500 \mathrm{mg}) \text {, ceftriaxone }(1000 \mathrm{mg}) \text {, dexamethasone } \\
(6 \mathrm{mg}) \text {, vitamin C (1000 mg), and zinc }(220 \mathrm{mg})\end{array}$ \\
\hline Day 2 & 36.9 & 3.1 & $4 \mathrm{mg}$ & $100 \mathrm{mg}$ & Same as above \\
\hline Day 3 (07:28) & 54.5 & 4.6 & Hold & $100 \mathrm{mg}$ & Same as above \\
\hline Day 3 (11:01) & 58.4 & 4.9 & Hold & $100 \mathrm{mg}$ & Discharged \\
\hline
\end{tabular}

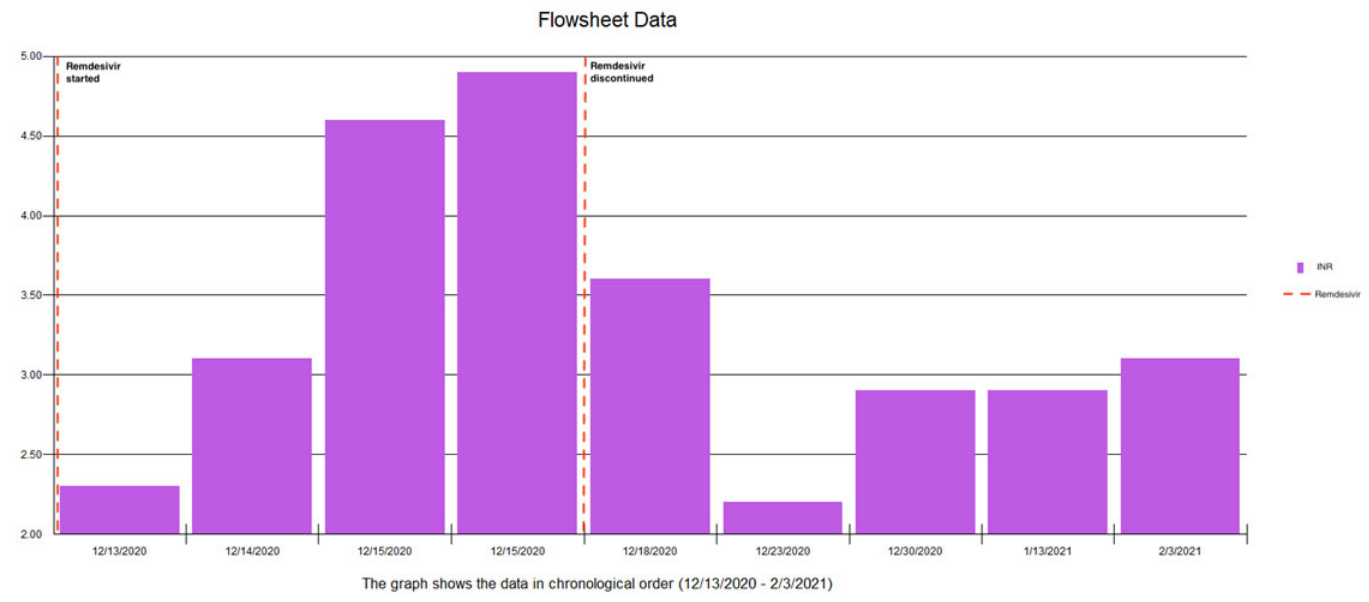

Figure 1. Patient's inpatient and outpatient INR trends 
Table 2. Patients anticoagulation profile at QHC Coumadin clinic. INR goal 2.5-3.5

\begin{tabular}{|c|c|c|c|c|c|}
\hline $\begin{array}{l}\text { Outpatient } \\
\text { Day }\end{array}$ & PT & INR & Warfarin Dose & Remdesivir & Comments \\
\hline Day 1 & - & - & Hold & Discontinued & $\begin{array}{l}\text { Missed appointment-patient instructed to hold } \\
\text { warfarin for two days. Return to clinic in } 2 \text { days. }\end{array}$ \\
\hline Day 3 & 43.0 & 3.6 & $6 \mathrm{mg}$ & Discontinued & $\begin{array}{l}\text { Continue warfarin } 6 \mathrm{mg} \text { until next clinic appointment } \\
\text { in } 5 \text { days. Plan to resume to regular dose if INR } \\
\text { continues down trending. }\end{array}$ \\
\hline Day 8 & 25.8 & 2.2 & $\begin{array}{l}10 \mathrm{mg} \\
\text { except } \\
\text { Monday/Thursday. } \\
4 \mathrm{mg} \text { Monday and } \\
\text { Thursday }\end{array}$ & Discontinued & $\begin{array}{l}\text { Resume regular regimen. } \\
\text { Return to clinic in one week for INR levels. }\end{array}$ \\
\hline Day 15 & 34.2 & 2.9 & $\begin{array}{l}\text { Continue regular } \\
\text { regimen }\end{array}$ & Discontinued & Return to clinic in two weeks for INR levels \\
\hline Day 29 & 33.6 & 2.9 & $\begin{array}{l}\text { Continue } \\
\text { regimen }\end{array}$ & Discontinued & Return to clinic in three weeks for INR levels \\
\hline Day 50 & 36.3 & 3.1 & $\begin{array}{l}\text { Continue } \\
\text { regimen }\end{array}$ & Discontinued & Return to clinic in three weeks for INR levels \\
\hline
\end{tabular}
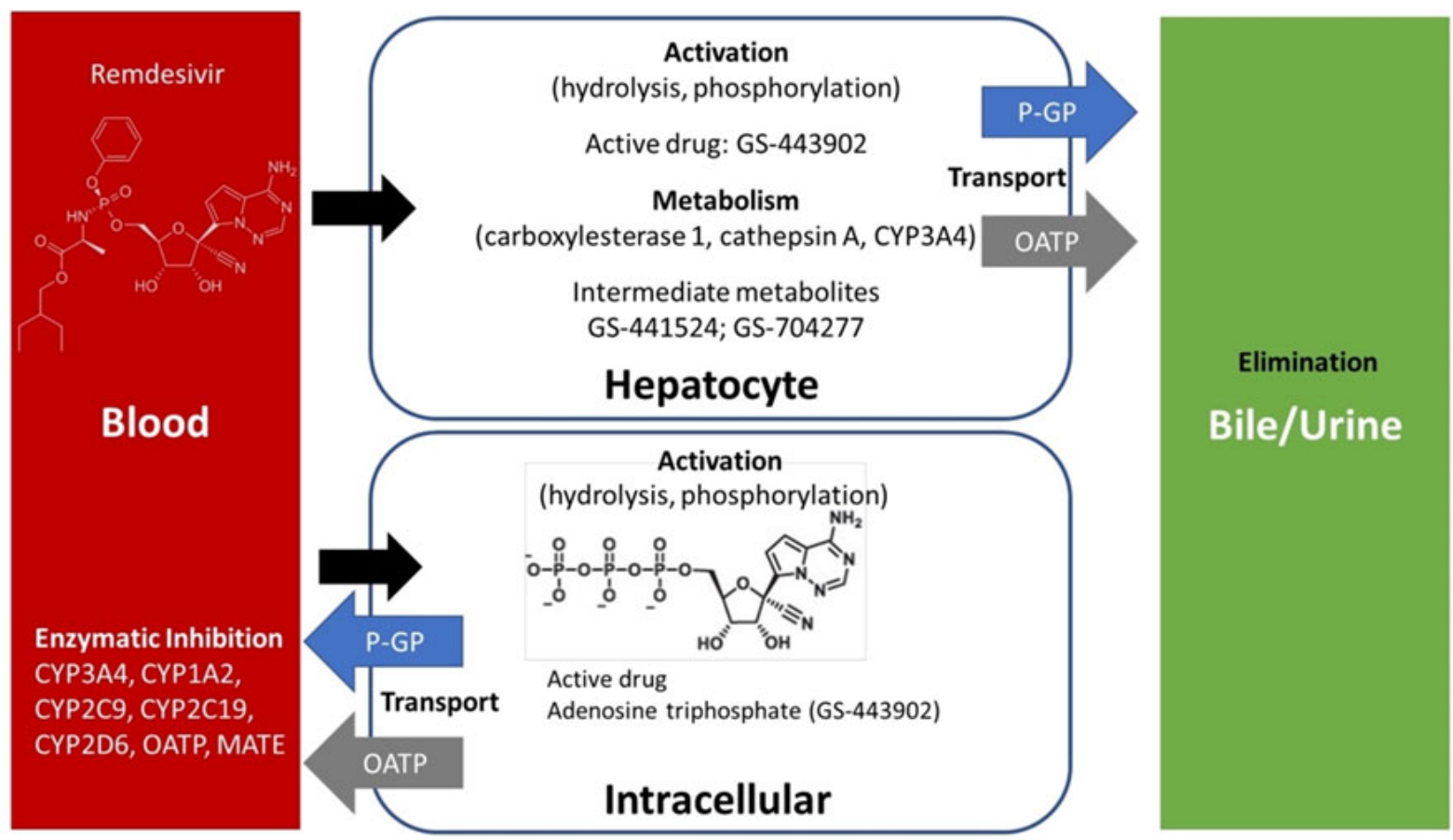

Figure 2. Enzymatic and transport processes involved in remdesivir pharmacokinetics. Adapted from Leegwater 2020. ${ }^{[8]}$ Permission obtained via Copyright Clearance Center, RightsLink

\section{DiscuSsion}

We report a case of INR elevation after initiation of remdesivir for COVID-19 pneumonia in a patient on stable chronic warfarin therapy prior to admission. The INR remained supratherapeutic after discontinuation of remdesivir and returned to therapeutic levels approximately eight days after Published by Sciedu Press discontinuation. The Naranjo Adverse Drug Reaction Probability Scale was to be 4 , indicating a possible adverse drug reaction.

The mechanism by which remdesivir increases the INR in patients on warfarin is unclear at this time. One possible 
explanation is through cytochrome enzyme inhibition as exemplified in Figure 2. In vitro, remdesivir was found to be an inhibitor of CYP3A4 and a weak inhibitor of CYP1A2, CYP2C9, CYP2C10 and CYP2D6. ${ }^{[9]}$ Warfarin is a racemic mixture of the R-enantiomer and S-enantiomer. The Sisomer is more potent than the $\mathrm{R}$-isomer and is metabolized primarily by CYP2C9, ${ }^{[10]}$ the same CYP enzyme that is weakly inhibited by remdesivir. It is plausible that decreased metabolism of warfarin through remdesivir-mediated CYP enzyme inhibition may have contributed to the INR elevation in our patient.

Utilization of corticosteroids in this patient may have also contributed to elevations in the INR. Previous studies have shown that the concomitant use of warfarin and shortterm corticosteroids such as dexamethasone or methylprednisolone resulted in INR elevations to supratherapeutic levels. ${ }^{[11]}$ The mechanism of this interaction is not well understood at this time but may be due to altered hepatic metabolism of warfarin by corticosteroids as a result of competitive binding at CYP3A4. ${ }^{[11]}$

Another possible contributor to INR elevations is the use of anti-infectives such ceftriaxone. Compared to other commonly used anti-infectives, ceftriaxone use was associated with a statistically significant higher peak INR value in patients managed with chronic warfarin therapy. ${ }^{[9]}$ Although the mechanism of interaction is not well defined, INR elevation is likely secondary to disruption of intestinal flora production of vitamin $\mathrm{K}^{\left[{ }^{[9]}\right.}$

\section{Conclusion}

Remdesivir is currently recommended for the management of COVID-19 infection. We report a case of possible remdesivirinduced PT/INR elevation in a patient receiving corticosteroids, anti-infectives, and chronic warfarin therapy. The peak INR was detected on day four of remdesivir therapy and returned to target therapeutic levels on day eight after discontinuation of remdesivir. The INR should be closely monitored and dosages should be adjusted accordingly in patients managed with remdesivir and warfarin therapy. Special consideration should be taken for patients on anticoagulation such as Warfarin to avoid possible life threatening complications. Clinicians should be mindful and consistently monitor patients on both Warfarin and Remdesivir for rising INR levels and adjust dosing appropriately.

\section{CONFlicts OF InTEREST Disclosure}

The authors have declared no conflicts of interest.

\section{REFERENCES}

[1] Warren TK, Jordan R, Lo MK, et al. Therapeutic efficacy of the small molecule GS-5734 against Ebola virus in rhesus monkeys. Nature. 2016; 531(7594): 381-385. PMid:26934220. https://doi.org/ $10.1038 /$ nature 17180

[2] Ali MJ, Hanif M, Haider MA, et al. Treatment Options for COVID19: A Review. Frontiers in Medicine. 2020; 7: 480. PMid:32850922. https://doi.org/10.3389/fmed.2020.00480

[3] de Wit E, Feldmann F, Cronin J, et al. Prophylactic and therapeutic remdesivir (GS-5734) treatment in the rhesus macaque model of MERS-CoV infection. Proceedings of the National Academy of Sciences of the United States of America. 2020; 117(12): 6771-6776. PMid:32054787. https://doi.org/10.1073/pnas.192208311 7

[4] Pan H, Peto R, Henao-Restrepo AM, et al. Repurposed Antiviral Drugs for Covid-19 - Interim WHO Solidarity Trial Results. The New England Journal of Medicine. 2021; 384(6): 497-511. PMid:33264556. https://doi.org/10.1056/NEJMoa2023184

[5] Zampino R, Mele F, Florio LL, et al. Liver injury in remdesivirtreated COVID-19 patients. Hepatology International. 2020; 14(5): 881-883. PMid:32725454. https://doi.org/10.1007/s12072 $-020-10077-3$

[6] Olry A, Meunier L, Délire B, et al. Drug-Induced Liver Injury and COVID-19 Infection: The Rules Remain the Same. Drug safety.
2020; 43(7): 615-617. PMid:32514859. https://doi.org/10.1 007/s40264-020-00954-z

[7] Manigaba K, Hawks J, Kima M. Remdesivir-Warfarin Interaction: A Case Report. HCA Healthcare Journal of Medicine. 2020; 1: 0 https://doi.org/10.36518/2689-0216.1164

[8] Leegwater E, Strik A, Wilms EB, et al. Drug-induced Liver Injury in a Patient With Coronavirus Disease 2019: Potential Interaction of Remdesivir With P-Glycoprotein Inhibitors. Clinical infectious diseases: an official publication of the Infectious Diseases Society of America. 2021; 72(7): 1256-1258. PMid:32594120. https://doi.org/10.1093/cid/ciaa883

[9] Saum LM, Balmat RP. Ceftriaxone Potentiates Warfarin Activity Greater Than Other Antibiotics in the Treatment of Urinary Tract Infections. Journal of Pharmacy Practice. 2021; 29(2): 121-124. PMid:25092605. https://doi .org/10.1177/08971900145447 98

[10] Holbrook AM, Pereira JA, Labiris R, et al. Systematic Overview of Warfarin and Its Drug and Food Interactions. Arch Intern Med. 2005; 165(10): 1095-1106. PMid:15911722. https://doi .org/10.100 1/archinte.165.10.1095

[11] Hazlewood KA, Fugate SE, Harrison DL. Effect of oral corticosteroids on chronic warfarin therapy. The Annals of Pharmacotherapy. 2006; 40(12): 2101-2106. PMid:17119104. https : //doi .org/10 .1345/aph. $1 \mathrm{H} 418$ 